\title{
COMPARISON OF THE EFFICACY OF HOMEMADE AND INDUSTRIALLY MADE ANFO EXPLOSIVES AS AN IMPROVISED EXPLOSIVE DEVICE CHARGE
}

More than $95 \%$ of all the terrorist attacks are carried out using the ANFO explosives. The ANFO explosives are explosives made from ammonium nitrate and fuel oil. They can be in three different variants (ammonium nitrate with oil, ammonium nitrate with oil and aluminium powder or ammonium nitrate with oil and TNT). This paper describes analysis of the field test results of ANFO explosives of different types. The efficacy of industrially made and the homemade ANFO explosives is compared and their possible usage in terrorist attacks for the treatment or the damage of critical infrastructure elements is described.

Keywords: ANFO explosives, field tests, homemade explosives, industrially made explosives, explosive device charge, critical infrastructure element

\section{Introduction}

The global threat of terrorism presents a grave security problem in the 21 st century. Combating this threat in the coming decades will require constant adjustment of forces, concepts, as well as capacities. Those changes will also affect the issues of protection of persons and property in the civilian environment. Improvised explosive devices (IED) as means of asymmetric threat in the present, as well as in the future, pose significant threat for the democratic states. IEDs are insidious and effective weapons being used by terrorists, alien militants and criminals, primarily for the purpose of crippling or killing people, destroying country's economy or for instilling fear among the civilians. Their aim is to challenge the legitimacy of governments and their ability to give their citizens freedom and security. Where the democratic processes end, the radical solution begins [1].

More than $95 \%$ of all the terrorist attacks are carried out using the ANFO explosives or other type of agents [2] and [3] After the human targets, elements of the critical infrastructure are the second most important target. The critical infrastructure element can be from one of critical element sectors (government buildings, embassies, traffic nodes - airports, railways and bus stations, banks, hospitals, dams, pipe infrastructure, power or information centers and others). As is obvious from the [4] those elements have greater safety risks and are the objects, the security breach of which can cause extensive damage, not only in terms of protection of human life and health, but also to the economy and to the performance of state functions.

\section{ANFO explosives}

The ANFO explosive is a widely used explosive mixture. It can be prepared industrially or it can also be made at home very easily.

From the chemical-technological point of view it is possible to differentiate three different versions of the ANFO explosives:

- ammonium nitrate + fuel,

- ammonium nitrate + fuel + powder metal (usually aluminium or magnesium) and

- ammonium nitrate + fuel + wooden powder - delaborated TNT.

Optimal content of diesel or oil in ANFO is about 5.5-6\%, in porous AN about $10-11 \%$. Mixture where the fuel content is less than the optimum decreases the energy of the explosion while simultaneously significantly increases the content of nitrogen oxides in products of the explosion. On the contrary, the higher content of fuel leads to an increase in the content of carbon

\footnotetext{
* ${ }^{1}$ Lucia Figuli, ${ }^{2}$ Vladimir Kavicky, ${ }^{\text {'Stefan Jangl, }{ }^{1} \text { Zuzana Zvakova }}$ 

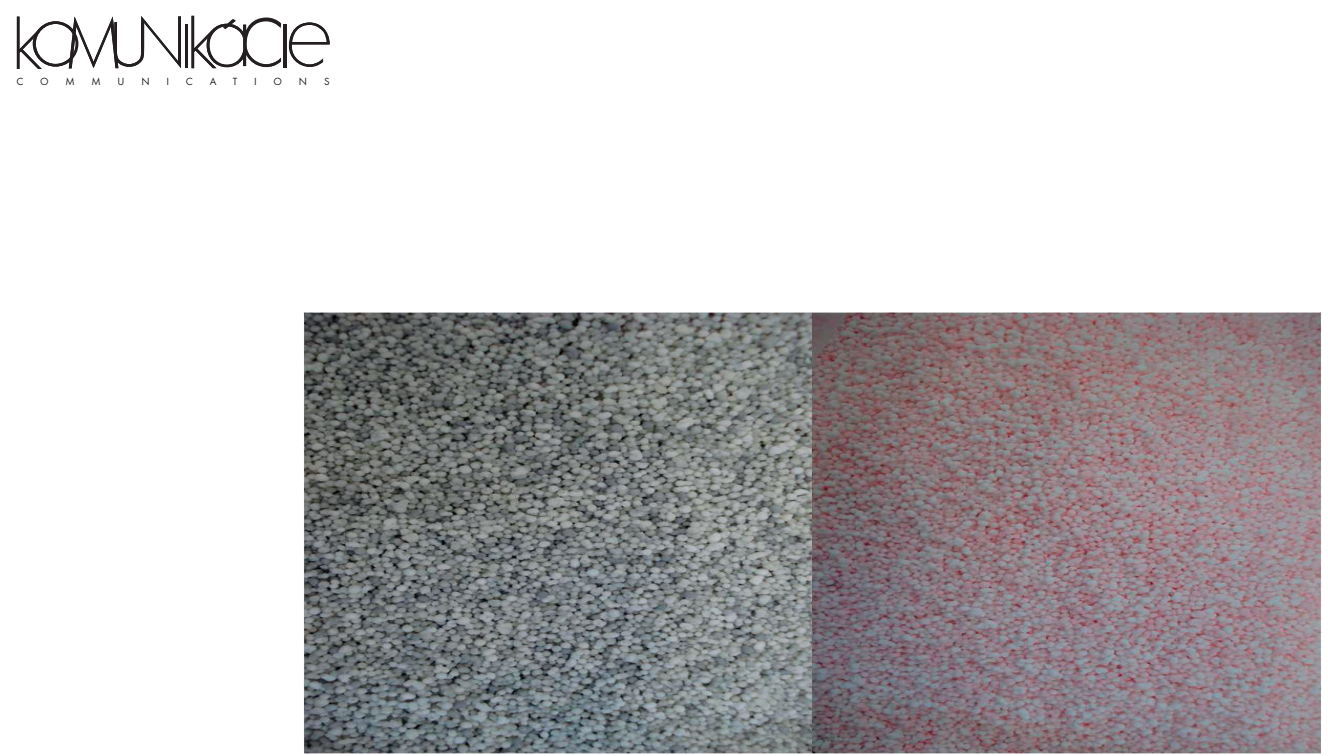

Figure 1 Industrially made explosives DAP - E (left) and DAP - 2 (right) in the prilled form

monoxide in the products of the explosion and again to a decrease in the energy of the explosion.

ANFO under the most conditions is considered as highly explosive; it decomposes through detonation rather than deflagration and with a high velocity. It is a tertiary explosive consisting of distinct fuel and oxidizer phases and requires confinement for efficient detonation and brisance. Its sensitivity is relatively low; it generally requires a booster (e.g., one or two sticks of dynamite, as historically used, or in more recent times, Tovex or cast boosters of TNT/PETN or similar compositions) to ensure reliable detonation [5].

This type of explosive is used in coal mining, quarrying, metal mining where its good characteristics as low cost and easiness of use matter more than the benefits offered by conventional industrial explosives, such as water resistance, oxygen balance, high detonation velocity and performance in small diameters is taken advantage.

The ANFO explosives are very popular among the terrorists due to their simplicity of preparation. They were the main explosives used by organizations such as IRA, PIRA, Al-Quaeda. The ANFO explosives were used for the terrorist attacks in New York, in Oklahoma City and Oslo. They are used by semi armed units in Afghanistan, Iraq, Syria and North Caucasus.

The ANFO explosives are present in improvised explosive devices, where they are also known as fertilizer bombs.

\section{Industrially made ANFO explosives}

The basic components of the first ANFO explosives were based on fertilizer ammonium nitrate and charcoal. The improvement of explosives began when the charcoal was substituted for hydrocarbon as fuel oil and fertilizer ammonium nitrate for technical one. Later, the crystalline ammonium nitrate was substituted for porous prilled one. This type of ammonium nitrate is produced so that the prills in a size of $0.5-3.0 \mathrm{~mm}$ are created. Blasting grade AN prills are made by spraying molten AN into a prilling tower (see Figure 1). Droplets fall under carefully controlled cooling conditions. The AN solidifies while falling, taking on an approximately spherical shape of relatively uniform size. Prilling tower conditions must enable production of a "porous" prill that will absorb the proper amount of fuel oil (6 percent by weight). High density prills will not properly absorb the fuel oil and blasting performance will suffer [6]. Prilled ammonium nitrate is capable to absorb 11 percent of fuel oil weight. The final explosive characteristics of prepared ANFO depend on the sizes and porosity of prills (on the density). Generally, ANFO with small porous prills has a higher detonation velocity and the higher detonation sensibility [7]. Dense prills are often not detonable, or if initiated, perform at very low rate of detonation [6].

For this research the products DAP - 2, DAP - E (see Figure 2) and POLONIT, manufactured by a of the Slovak company called Istrochem Explosives a.s. Bratislava, were chosen. Their characteristics and the represented type of explosive are given in Table 1. It should be pointed out that all used explosives were fabricated industrially, meeting the standards of the production technology.

\section{$D A P$ - 2}

The explosive is a mixture of ammonium nitrate, kerosene and dye. The explosive is of loose consistency, red in colour and is used for blasting on the surface, as well as is in the underground, without the danger of gas, vapour and dust explosions as a rock mining explosive.

\section{$D A P$ - E}

The explosive is a mixture of ammonium nitrate, methyl esters of higher fatty acids, vegetable oil and red dye. The explosive is of loose consistency, red-grey in colour and it can be used in blasting operations on the surface, as well as in the underground, in an environment without the danger of gas, vapour and dust explosions as a rock mining explosive.

\section{POLONIT - $V$}

The explosive is a mixture of ammonium nitrate, kerosene, charcoal, ground TNT with water-resistant additives. The explosive is of loose consistency, white to yellowish in colour and it can be used in blasting works on the surface, as well as in 
Table 1 Characteristics of industrially made ANFO explosives

\begin{tabular}{|c|c|c|c|c|c|}
\hline Explosive & $\begin{array}{l}\text { Type of represented } \\
\text { ANFO explosive }\end{array}$ & $\begin{array}{l}\text { Explosive velocity } \\
{[\mathrm{m} / \mathrm{s}]}\end{array}$ & $\begin{array}{l}\text { Heat of combustion } \\
\qquad[\mathrm{kJ} / \mathrm{kg}]\end{array}$ & Density $\left[\mathrm{g} / \mathrm{cm}^{3}\right]$ & $\begin{array}{c}\text { Explosive pressure } \\
{[\mathrm{GPa}]}\end{array}$ \\
\hline DAP - 2 & $\mathrm{AN}+\mathrm{oil}$ & 2650 & 3830 & 0.65 & 2.95 \\
\hline DAP - E & $\mathrm{AN}+\mathrm{oil}+\mathrm{Al}$ & 3100 & 4200 & 0.65 & 4.58 \\
\hline Polonit - V & $\mathrm{AN}+$ oil+TNT & 4000 & 5138 & 0.9 & 6.93 \\
\hline TNT & Reference & 6800 & 4200 & 1.58 & 18.4 \\
\hline
\end{tabular}

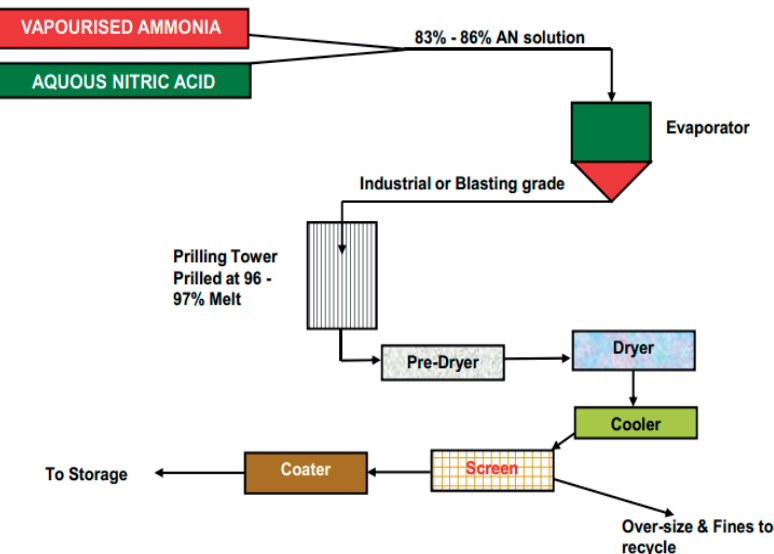

Figure 2 Ammonium nitrate prill manufacturing [6]

the underground, in an environment without the danger of gas, vapour and dust explosions.

\section{Homemade ANFO explosives}

These types of explosives are very dangerous for the society Prices of needed components are very low; the preparation does not require specialised knowledge and components for the preparation are freely available. Described explosives can be made by fertilizer based on ammonium nitrate used for agricultural purposes. Availability of fertilizers and oils (oil, fuel oil, kerosene) is not controlled. A malaxer for the production of chocolate or a concrete mixer can be used as mixing machines.

It is thought that the homemade explosives are not mixed well, made from low quality raw material (nitrogen content), they contain chemical impurities, possibly water and thus one can suppose that their efficiency is $70-90 \%$ of standardly fabricated explosives.

Blasting prill, considered a porous prill, better distributes the fuel oil (fuel oil distribution for fertilizer prill is on surface only and for blasting prill goes throughout prill) and results in much better performance on blasting job (velocity of detonation of fertilizer prill is $1829 \mathrm{~m} / \mathrm{s}$ and of blasting prill is $3353 \mathrm{~m} / \mathrm{s}$ ) [6]

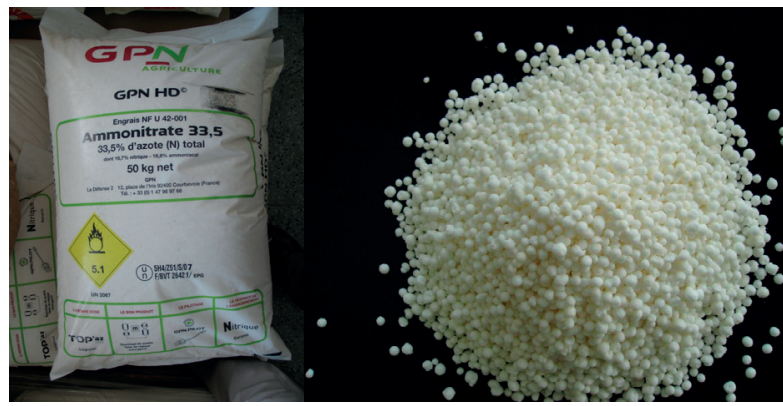

a)

b)

Figure 3 Ammonium nitrate used in the field tests a) sack b) prills

\section{Field tests}

The field tests were focused on the measurement of the overpressure differences in the homemade and industrially made ANFO explosives. The set of field tests took place at the development and testing set of the Ministry of Defence of the Slovak Republic called Military Technical and Testing Institute Zahorie. They took place in the period from 2011 to 2014. Methodology of the measurement is based on [8]. Maximum overpressure was measured using the blast pressure sensors type 137A23 and 137A24 PCB Piezotroics. The explosive charge was positioned at a wooden base at the height of $1.6 \mathrm{~m}$ over the ground, i.e. in the height of human chest. Sensors were placed at the distances of 2, 5, 10 and 20 meters from the source (see Figure 5). Besides the maximum overpressure, the velocity of blast wave and the noise level were also measured.

The GPN HD Ammonitrate 33.5 (composed of 33.5\% of ammonium nitrate - $16.7 \%$ of nitric nitrogen and $16.8 \%$ of ammoniacal nitrogen) and fuel oil Extra M2T (5\% of charge weight) (see Figure 3) were used for the preparation of ANFO explosives for the blast tests. The shape of explosives was cylindrical and the explosive material was wrapped in a cardboard cover not to influence the resultant value of overpressure.

The two types of homemade ANFO explosives and three types of industrially made ANFO explosives were used in the field tests. One was Ammonium nitrate with the fuel oil and the second type was a pure Ammonium nitrate. The explosives were used together with $20 \mathrm{~g}$ of ignition explosive PLNp10 and the weight 


\section{kam NikCle}

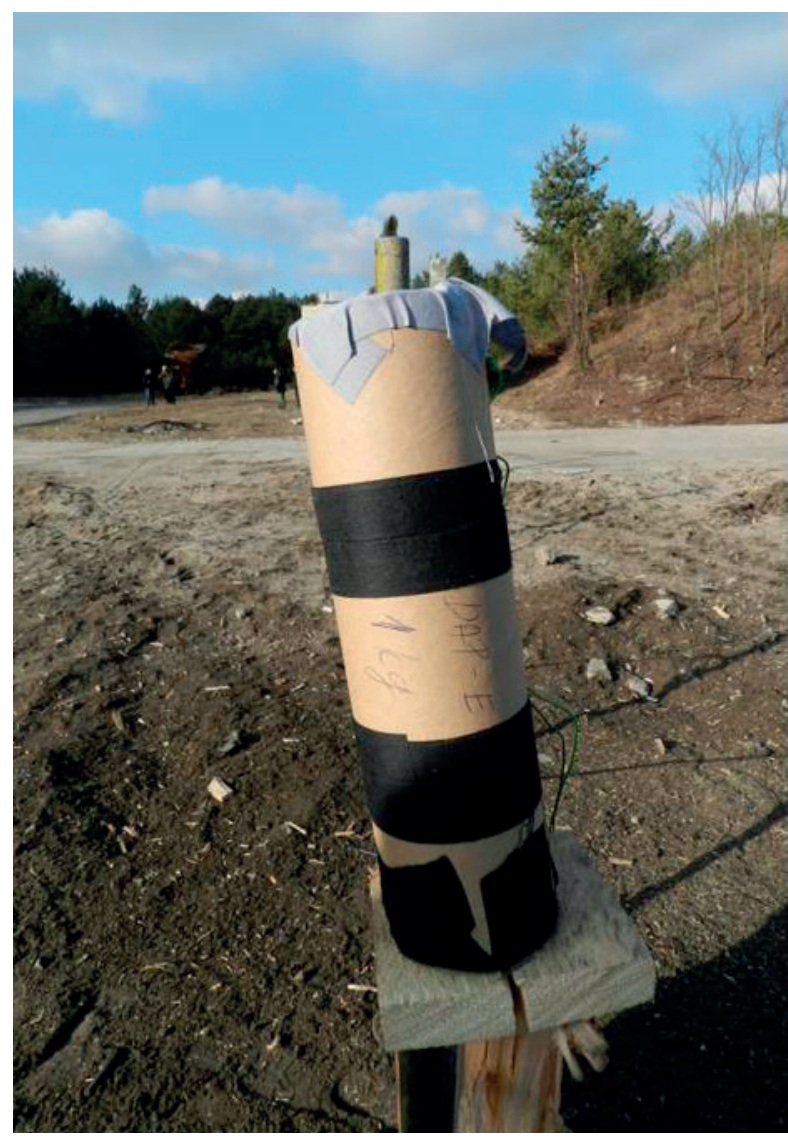

Figure 4 Explosive DAP - E weight $1000 \mathrm{~g}$ for field test

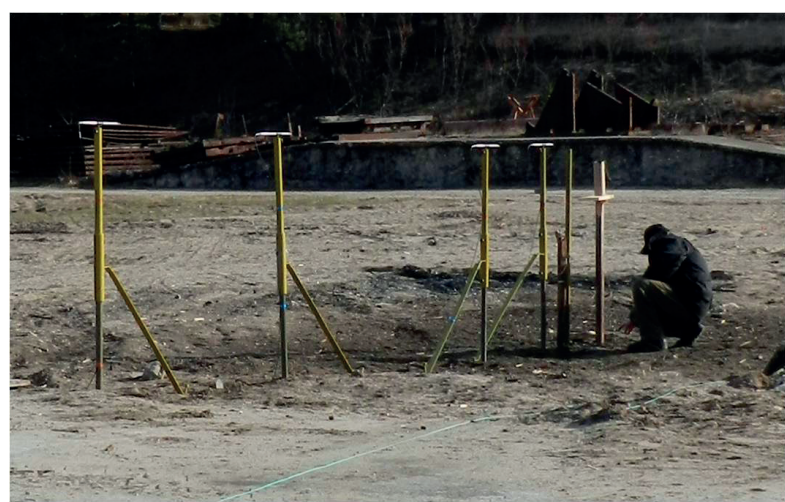

Figure 5 Preparation of measuring sensors for field tests

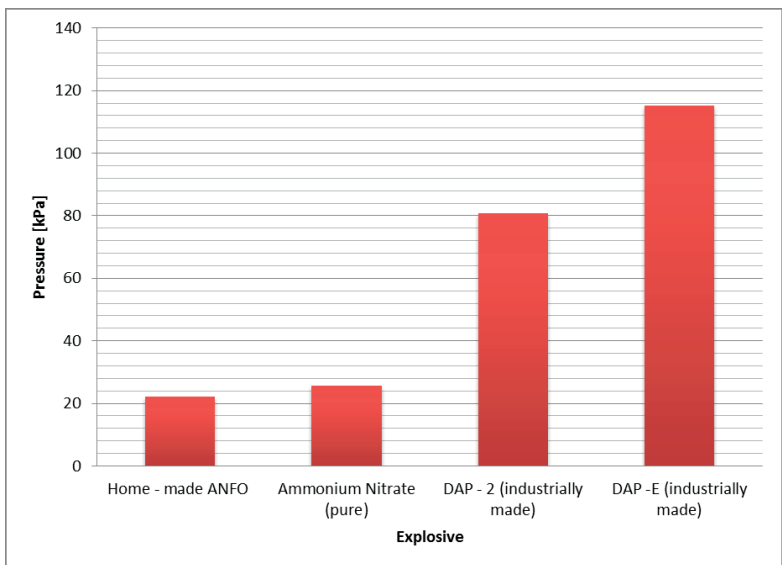

Figure 6 Maximum pressure of homemade and industrially made ANFO explosives

Table 2 Comparison of industrially made and homemade ANFO explosives

\begin{tabular}{ccccc}
\hline Explosive & $\begin{array}{c}\text { Type of } \\
\text { represented ANFO explosive }\end{array}$ & Pressure [kPa] & Difference & \multicolumn{2}{c}{ Difference } \\
{$[\mathbf{k P a}]$} & & 60.9 & $7 \%]$ \\
\hline Industrially made ANFO & AN + oil & 20.2 & 60.7 & 75.03 \\
Homemade ANFO & AN + oil & & \\
\hline
\end{tabular}

of charges was $1000 \mathrm{~g}$ (see Figure 4). From industrially made ANFO explosives the products DAP - 2, DAP - E (see Figure 2) and POLONIT were chosen. In the case of pure ammonium nitrate there was an uncompleted detonation of the explosive and the portion of ammonium nitrate prills was spread into the environment in the radius of $3.5 \mathrm{~m}$ from the explosive source.

The measured data of the ANFO explosives were chosen for the comparison at the distance of $2 \mathrm{~m}$ from the explosive source. The maximum over pressure of the homemade and industrially made ANFO explosives, used in the field tests, are shown in Figure 6. From the comparison it is obvious that the homemade ANFO explosives feature the lower efficacy than the industrially made ones. There is a big difference between the different types of industrially made ANFO explosives, which presents three different types of possible ANFO explosives.
Table 2 shows the comparison of average overpressure of industrially and homemade explosives of the same explosives type from the field tests.

\section{Conclusion}

The results of the presented field tests as from the field tests conducted by J. Stoller [9], [10] demonstrated the difference between the homemade and industrially made ANFO explosives. The homemade explosives have by $75 \%$ lower efficacy than the industrially made ones. It was confirmed that the differences of preparation between explosives (homemade explosives are not mixed well, made from the low quality raw material (nitrogen content), they contain chemical impurities and water, and blasting 
prills are porous prills, which better distribute the fuel oil) influences the efficacy of the explosive.

When the safety of persons and property is being considered, safety treatment measures are based on the values of industrially made explosives. More than $95 \%$ of all the terrorist attacks are carried out using the homemade ANFO explosives and therefore the treatment measures employed for the protection are sufficient and even overcharged.

\section{References}

[1] KAVICKY, V., FIGULI, L., JANGL, S., LigasovA, Z.: Analysis of the Field Test Results of Ammonium Nitrate Fuel Oil Explosives as Improvised Device Charges. WIT Transactions on the Building Environment, 141, 297-309, 2014.

[2] VANDLICKOVA, M.: Terrorism and the Possibility of CBRN Agents Misuse: Security Management and Society, electronic source (in Slovak). Proceedings of International Conference on University of Defence in Brno, Czech Republic, CD-ROM, 537-541, 2013.

[3] ORINCAK, M.: Hazardous Industrial Accidents of LPG Gasses. Proceedings of 11th International Scientific Conference Science 2003, Education and Society, Slovakia, section No. 6, 97-100, 2003.

[4] MANAS, P., KROUPA, L., URBAN, R., COUFAL, D.: Blast Threat to Critical and Military Infrastructure. Security and Defence Quarterly, 1, 32-53, 2013.

[5] COOK, M. A.: The Science of Industrial Explosives. IRECO Chemicals, 1974.

[6] SHARMA, P. D.: Presentation [online]. Available: http://www.slideshare.net/ sharmapd1/an-anfo-hanfo [accessed 2014-09-19].

[7] ZEMAN, S.: Technology of Basic Explosives - Lectures (in Czech). Fakulta Chemicko technologicka, Univerzita Pardubice, 2004.

[8] ITOP 4-2-822: Electronic Measurement of Airblast Overpressure and Impulse Noise, 2000.

[9] STOLLER, J., MANAS, P., ZEZULOVA, E.: Blast Testing and Simulation Methods. CVUT, Praha, p. 35-100, 2015.

[10] STOLLER, J., DVORAK, P.: Field Tests of Cementitious Composites Suitable for Protective Structures and Critical Infrastructure. Key Engineering Materials 722 KEM, 3-11, 2017. 